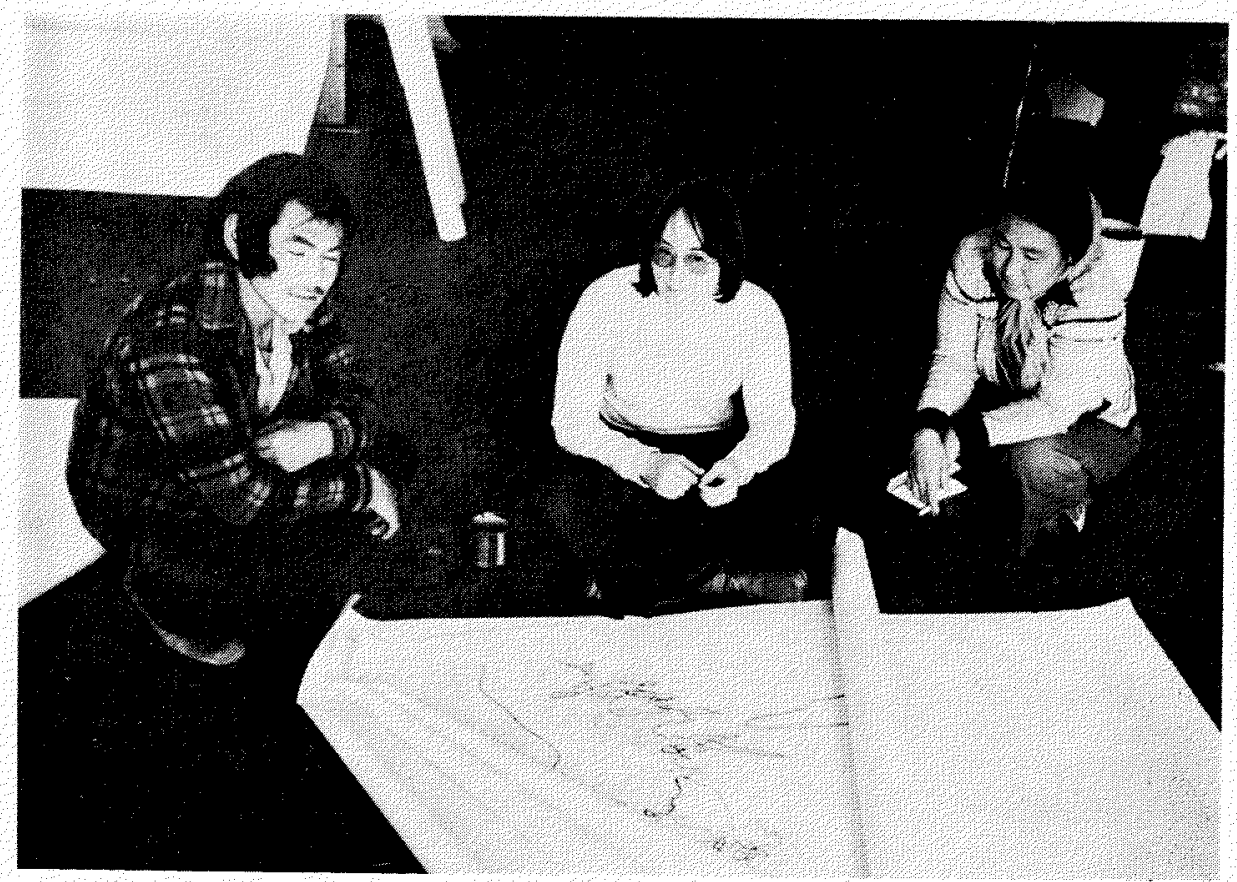

August 1976, Nain, Labrador. Eli Merkuratsuk, Carol Brice-Bennett and Christiana Kojak are discussing the maps then in preparation for the Labrador Inuit Association's land use and occupancy study. Plotograph by Alan Cooke. 


\title{
Science and Ethics in the North
}

\author{
MILTON M. R. FREEMAN ${ }^{1}$
}

Certain problems of a practical or stressful nature have always existed for scientists wishing to conduct their investigations in remote locations, but there are additional concerns today of more recent origin. I refer to the reaction of local populations to the ever-increasing numbers of scientists and other investigators who in their general attitudes seem to remain much the same as their predecessors. Adverse local reaction is caused not only by this recent increase in numbers, but by the continual and progressively irritating failure of the seasonal visitors to avoid some combination of a number of recognizable shortcomings, e.g.: failure to seek permission from the community before subjecting its members, their activities or their immediate environment to detailed examination; failure to consult with the residents as to whether, in their view, the study is appropriate or could be modified so as to cause less stress to them or their environment; failure to keep them informed of the course of the investigation thus precluding any mature involvement with them, or a degree of recognition or respect for their intellectual curiosity. As a final faux pas the departing investigators, after assuring some local people that a copy of the results will be sent to them, will only too likely fail to send back any report on the work they have carried out.

Doubtless this situation has been, until very recently indeed, experienced by all northern peoples, irrespective of the political jurisdiction under which they live. Thus the years of the International Biological Programme (IBP) may hopefully - at least as far as its Human Adaptability Project was concerned - go down in northern history as the last notable example of scientific imperialism. It is an embarrassment to most members of the international research community to have to be reminded, via reports and comments in the field, of the insensitivity and excesses of that enterprise. The following extract from a recent book (Ingold 1976) concerns a particular IBP assault:

Less (useful things) can be said for the massive series of investigations launched by the (IBP - Human Adaptability Section) of which the Skolt have been unwilling victims almost yearly since 1966 . ... The programme reached its climax in July 1969, when a team of over eighty investigators from nine countries covered by a posse of press, radio and television reporters ... set about making systematic anthropometric measurements and body tests on every man, woman and child ... at the rate of about forty a day. As an incentive subjects were offered free medical, dental and optical treatment. The ethnocentric attitude assumed by the investigators toward their subjects was little short of appalling, and overshadows any objective value their researches may have had... 
When, in 1971, UNESCO adopted a resolution establishing a seemingly even more ambitious scientific undertaking, namely the Man in the Biosphere (MAB) Programme, some misgivings were felt by a number of IBP-watchers, especially since such international multi-personnel projects seemed to be viewed in some quarters as an appropriate means of achieving limited, but desired, ends in international diplomacy as well as academic statesmanship.

As with the IBP before it, MAB was to be constituted as a many-tiered organization of working groups and committees at the local and topical, national and international levels.

In Canada, for example, four working groups were established to develop research frameworks for each of four sub-programmes dealing respectively with urbanization and industrialization, agriculture and forestry, coastal ecosystems, and the North. In this present paper I will comment upon and evaluate the initial report of the Working Group on Science for the North entitled Ethical Principles for the Conduct of Research in the North (MAB 1977a).

In fairness to this report, I should preface my remarks by the observation that its authors see it as a discussion paper. The problems they address are profound and important ones, for as has been observed in another recent report (Canada Council 1977),

... inherent in the problems of this research is a conflict of values ... the dilemma (to be resolved is) how to strike a proper balance between respect for the rights and sensibilities of the individual or collectivity, on the one side, and society's need for advancement of knowledge on the other.

The problem in achieving that proper balance is that not only is it delicate and shifting but that variable, culturally-influenced, perceptions of desired goals and attendant risks, benefits and disadvantages are the stuff to be placed on the scales.

There can be little argument but that scientific research is viewed with a somewhat jaundiced eye by many long-time northern residents for the good reasons noted above. Little reassurance can be offered that scientists are prospective savants rather than servants, when part of the justification for the recent issue by the Canadian government of Guidelines for Scientific Activities in Northern Canada (A.C.N.D. 1976) is stated in that leaflet to be

the recognized need for a concerted approach in directing research and scientific effort toward acquiring scientific knowledge in support of northern plans and programs.

These plans and programmes are, one must note, viewed by many northern residents today with the greatest apprehension and some foreboding.

To their credit, the MAB Working Group on Science for the North views as long-term goals the achievement of satisfactory codes of scientific practice. This is both realistic and proper; and, given the past lack of communication between the two communities involved, a sincere, deliberate and continuous process of mutual education is necessarily required. In fact, no one can accuse the Working Group of humanistic shortcomings; indeed its name alone indicates its intent, which is made explicit in the observation (MAB 1977b) that 
science that was planned and carried out specifically for problems as perceived by northern residents would be the fundamental step to assure maximum benefits and minimum adverse effects as industrial development and technological change continue to influence northern settlements.

The proposed ethical guidelines (MAB 1977a) are comprehensive and address the usual concerns of such codices, namely the requirements to be met in obtaining the informed consent of a community and its involvement in a research undertaking: the right to privacy and respect; accountability; acknowledgement; disposition of the data, and communication of the results of the research.

For the most part, I find little cause for disagreement with the guidelines. But some areas are troublesome in so far as practical problems appear to loom large and threaten compromise of an important ethical consideration, not mentioned in the guidelines, namely deception. This problem arises most acutely in meeting the proposed requirements for informed consent. I refer to the following guidelines:

B4. Investigators should take into account and make explicit the potential effects of their research on the environment and on the economic and social structure and services existing in the host community and areas of livelihood.

B5. In advance of their decision to participate, communities and participants should be informed by the investigator of both the positive and negative social consequences of their participation.

The point here, of course, is not only that scientific data may be misused or made to serve ends not in the best interests of the subjects of the research, but that the question "what use will data be put to" is, with total honesty, unanswerable by the investigator. Scientists may know to which policy-relevant areas their investigations are most germane, but generally they are neither privy to, nor especially adept at, influencing eventual policy decisions. Thus the degree to which the investigator has to gloss over, or hedge on, the complexity of the issues in order to meet requirements B4 and B5 borders on deception, which is altogether unacceptable.

The days when most thinking scientists believed they had some control over their research, or enlightened views as to the effects of it on humankind, are surely long past. It is now realized, even by academic researchers, that scientific "truths" are less the basis for policy and programme formulation than economic and political expediency. Any scientist offering assurances to people far from the centres of power and decision-making is at best venturing a hazardous opinion, and at worst, engaging in culpable deceit.

Another of my concerns, as a social scientist, is that any strict meeting of the requirements for informed consent may result, in some cases, in influencing the informant's response to questions that are to be researched, thereby destroying the very basis and acceptability of certain methodological approaches. The problem is perhaps more acute in some disciplines than in others, but in general I would agree with a recent observation that "new and rigid rules have all but eliminated this essential flexibility and opportunity for serendipity on which original discovery depends"' (Shneour 1977). 
What then is a possible solution to these practical problems? The MAB Working Group's concern and proposals are, up to a point, laudable and call for enlightened and normalized relations between outside scientist and local resident through a series of guidelines proposing a more cooperative approach to the practice of science in the field. Cynically, one might observe that such cooperation would in effect constitute a mechanism by which local residents became party to "the crime", though to be sure it would give them an opportunity to minimize some of the possible adverse effects.

What I would have expected the Working Group to state quite explicitly in the ethical guidelines is that, if certain types of research cannot be conducted without ethical compromise, they should be abandoned - not, I hasten to add, summarily, but only if an independent ethics committee fails to resolve the problems involved in a way satisfactory to all interests. The Canada Council (1977) document, addresses this matter in some detail.

My second main concern is, apparently paradoxically, that the proposed ethical principles do not go far enough! What more scientists have to realize is that accountability does not merely govern the conduct of the actual research, which is the position mostly embraced by the MAB Working Group. The conduct of research on human subjects and on those things of the utmost importance to the subjects' total well being (for example, their environment or culture) constitutes, in most cases, an intervention in their lives or, more properly, is one part of a series of changes that progressively affect the lives of everybody. Research may, for example, result in heightened self-awareness, or it may result in direct and profound alteration in peoples' ways of life due to the activities of powerful outside agencies over which those affected can exert little or no influence. The important point, however, is that in all cases the sequence of progressive changes, once under way, may be influenced by the research itself. Though all northern peoples have long been in contact with, and variously affected by, outside agencies, the interaction with scientists proposed in the ethical guidelines presupposes an involvement, personal and intellectual, that would be both new and profound. It follows from this, I believe, that scientists whose research has this potential effect must, if professing these new-found ethical concerns, be prepared to remain involved in the process they are part of, rather than opt in and opt out in a way that northern resident participants in their research cannot do.

In my view the leads taken already by certain groups of scientists must be seriously considered by many more scientists if the freedom to prosecute a whole range of research is to be maintained. The Canadian Arctic Resources Committee is an example of one such concerned scientific consortium, and the Harvard Kalahari Research Group and l'Association Inuksiutiit Katimajiit at Université Laval, Quebec, are others. The lead these and many other groups have demonstrated is the precedent to be followed, and scientists must increasingly come to recognize that regularizing only the planning-and-fieldwork phase of their professional activities does not go nearly far enough in today's world.

On the other hand, it is necessary to stress that no group's culture can come to be regarded by that group as a private possession, to which access may be denied to those who genuinely wish to understand, marvel at and cherish it too. To be 
sure, there may be aspects of a culture which are properly secret or access to which may require inherited rights, but such exceptions are usually kept from outsiders without difficulty. Knowledge of another person's culture or language enriches rather than depauperizes, so that the integrity and capability of the individual seeking to transmit that knowledge should be the deciding factor, not that person's ethnicity or professional affiliation.

The last point I wish to make, with some force, is that although consultation of local people should take place concerning any research to be undertaken, it is likely to be meaningful only in respect to certain aspects of the work. For example, local people might wish to suggest that a change in emphasis or content would benefit them more than the submitted proposals appeared to, and almost certainly they would be likely to be able to correct any gross ethnocentricism that might appear in the research proposals. However, once the nature of the discussion turns on "appropriateness" there is a danger that the independent goals of science on the one hand and expediency on the other will become confused and thrown into unseemly competition. What I wish to say, with some emphasis, is that vetoing "pure research", i.e., that which offers no apparent or immediate benefit to humankind, will only serve to blunt the intellectual growth of Western society, a society not all may wish to join, but some aspects of whose culture other civilizations may wish to selectively embrace and perhaps benefit from.

\section{REFERENCES}

A.C.N.D. (Advisory Committee on Northern Development). 1976. Guidelines for Scientific Activities in Northern Canada. Ottawa: Department of Indian and Northern Affairs.

CANADA COUNCIL. 1977. Ethics: Report of the Consultative Committee on Ethics. Ottawa: Canada Council. p. 1.

INGOLD, T. 1976. The Skolt Lapps Today. Cambridge: Cambridge University Press. p. 12. MaB (Canadian Man-and-the-Biosphere Programme). 1977a. Ethical Principles for the Conduct of Research in the North. Ottawa: Environment Canada, Liaison and Coordination Directorate (Canadian Communiqué no. 6).

1977b. Sub-programme 4-Science for the North: Research Framework. Ottawa: Canadian Committee for MAB and Interdepartmental Committee for MAB (Report no. 8, January 1977). p. 2.

SHNEOUR, E. A. 1977. Science: too much accountability? Science, 195: 939. 